\title{
Sarilumab versus standard of care for the early treatment of COVID-19 pneumonia in hospitalized patients: SARTRE: a structured summary of a study protocol for a randomised controlled trial
}

\author{
Antonio F. Caballero Bermejo ${ }^{1}$, Belén Ruiz-Antorán ${ }^{1 *}$ (D), Ana Fernández Cruz² , Elena Diago Sempere ${ }^{1}$, \\ Alejandro Callejas Díaz², Elena Múñez Rubio², Cristina Avendaño-Solá', Antonio Ramos Martínez², \\ Aránzazu Sancho López ${ }^{1}$ and Puerta de Hierro COVID-19 Study Group
}

\begin{abstract}
Objectives: In some patients, acute, life-threatening respiratory injury produced by viruses such as SARS-CoV and other viral pneumonia are associated with an over-exuberant cytokine release. Elevated levels of blood IL-6 had been identified as a one of the risk factors associated with severe COVID-19 disease.

Anti-IL6 inhibitors are among the therapeutic armamentarium for preventing the fatal consequences of acute respiratory and multi organ failure in around 20\% of the COVID-19 infected patients. At present, their use is prioritized to patients with severe interstitial pneumonia (Brescia-COVID Scale-COVID 2-3) with hyperinflammation as determined by the presence of elevated IL6 and/or d-dimer, or progressive d-dimer increase, in patients who otherwise are subsidiary to ICU admission. However, many uncertainties remain on the actual role of anti-IL6 inhibitors in this setting, and whether current use and timing is the right one. There is the hypothesis that the use of anti-IL6 inhibitors at an earlier state during the hyperinflammatory syndrome would be beneficial and may avoid progressing to ARDS. On the other hand, the standard of care has changed and nowadays the use of corticosteroids has become part of the SOC in the treatment of COVID-19 pneumonia. Our limited experience suggests that better treatment outcomes can be achieved when combining IL6-inhibitors (e.g. sarilumab) with corticosteroids.

The aim of the present study is to evaluate if an earlier therapeutic intervention with sarilumab plus SOC (including corticosteroids) may be more effective than current standard of care alone, in preventing progression to respiratory failure in COVID-19 infected patients with interstitial pneumonia. This study will also provide supportive evidence to that provided by currently ongoing studies on the efficacy and safety of sarilumab in this clinical context.

(Continued on next page)
\end{abstract}

\footnotetext{
* Correspondence: mariabelen.ruiz@salud.madrid.org

${ }^{1}$ Clinical Pharmacology Department, Hospital Universitario Puerta de

Hierro-Majadahonda, Instituto de Investigación Sanitaria Puerta de Hierro

Segovia de Arana, Madrid, Spain

Full list of author information is available at the end of the article
}

C The Author(s). 2020 Open Access This article is licensed under a Creative Commons Attribution 4.0 International License, which permits use, sharing, adaptation, distribution and reproduction in any medium or format, as long as you give appropriate credit to the original author(s) and the source, provide a link to the Creative Commons licence, and indicate if changes were made. The images or other third party material in this article are included in the article's Creative Commons licence, unless indicated otherwise in a credit line to the material. If material is not included in the article's Creative Commons licence and your intended use is not permitted by statutory regulation or exceeds the permitted use, you will need to obtain permission directly from the copyright holder. To view a copy of this licence, visit http://creativecommons.org/licenses/by/4.0/. The Creative Commons Public Domain Dedication waiver (http://creativecommons.org/publicdomain/zero/1.0/) applies to the data made available in this article, unless otherwise stated in a credit line to the data. 
(Continued from previous page)

Trial design: A phase two multi-center randomised controlled trial (RCT) with two parallel arms (1:1 ratio).

Participants: They will be hospitalized patients, of at least 18 years of age, with severe COVID-19 who have positive RT-PCR test and have radiographic evidence of pulmonary infiltrates by imaging or rales/crackles on exam and $\mathrm{SpO} 2 \leq 94 \%$ on room air that requires supplemental oxygen. Patients must present elevation of inflammatory parameters (IL-6 $>40 \mathrm{pg} / \mathrm{mL}$ or d-dimer $>1.0 \mathrm{mcg} / \mathrm{ml}$ ) or, alternatively, progressive worsening in at least two of these inflammatory parameters in the prior 24-48h: CRP, LDH, serum ferritin, lymphopenia, or d-dimer.

Exclusion criteria: high oxygen requirements (including face mask with reservoir, non-invasive mechanical ventilation or high flow nasal cannula, or mechanical ventilation), admission to ICU, pregnancy or lactation, allergy or hypersensitivity to sarilumab or corticoesteroids, immunosuppressive antibody therapy within the past 5 months, AST/ALT values > $10 \times U L N$, neutropenia $(<0.5 \times 109 / L)$, severe thrombocytopenia $(<50 \times 109 / L)$, sepsis caused by an alternative pathogen, diverticulitis with risk of perforation or ongoing infectious dermatitis.

The study will be conducted in several hospitals in Spain.

Intervention and comparator: Patients randomised to the experimental arm will receive sarilumab + methylprednisolone plus SOC for COVID-19. Patients included in the control arm will receive methylprednisolone plus SOC for COVID-19. Corticosteroids will be given to all patients at a $1 \mathrm{mg} / \mathrm{kg} / \mathrm{d}$ of methylprednisolone for at least 3 days. Clinical follow-up visits will be performed at 3, 5, and 15 days after treatment randomization. Patients in the control group (SOC group without sarilumab) progressing to Brescia- COVID 2-3 plus inflammatory markers, will be given the option to be rescued with sarilumab at the same doses and, in that case, be included in an open-label phase and be followed up for additional weeks (with visits at 3, 7 and 15 days after sarilumab rescue administration). Patients randomly assigned to sarilumab therapy at baseline progressing to Brescia-COVID 2-3 will be rescued according to local clinical practice protocols.

A final follow-up visit will be conducted for all patients at day 29 from randomization, regardless of initial treatment assignment.

Main outcomes: Primary end point is the proportion of patients progressing to either severe respiratory failure (Brescia-COVID $\geq 2$ ), ICU admission, or death.

Randomization: Randomization codes were produced by means of the PROC PLAN of the SAS system, with a 1:1 assignment ratio, stratifying by centre and using blocks multiple of 2 elements. The randomization schedule will be managed through the eCRF in a concealed manner.

Blinding (masking): All study drugs will be administered as open label. No blinding methods will be used in this trial.

Numbers to be randomised (simple size): The target sample size will be 200 COVID-19 patients, who will be allocated randomly to control arm (100) and treatment arm (100).

Trial status: Protocol Code: SARTRE Protocol Date: May 05th 2020. Version: 2.0

The study has been approved by the Spanish Competent Authority (AEMPS) as a low intervention clinical trial. Start of recruitment: August, 2020

End of recruitment: May, 2021

Trial registration: Identifier: EudraCT Number: 2020-002037-15; Registration date: 26 May 2020.

Full protocol: The full protocol is attached as an additional file, accessible from the Trials website (Additional file 1). In the interest in expediting dissemination of this material, the familiar formatting has been eliminated; this letter serves as a summary of the key elements of the full protocol.

The study protocol has been reported in accordance with the Standard Protocol Items: Recommendations for Clinical Interventional Trials (SPIRIT) guidelines (Additional file 2).

Keywords: COVID-19, SARS-CoV-2, Randomised controlled trial, protocol, sarilumab, anti-IL6 inhibitor, severe interstitial pneumonia, corticosteroids, early intervention 


\section{Supplementary information}

Supplementary information accompanies this paper at https://doi.org/10. 1186/s13063-020-04633-3.

Additional file 1. Full Study Protocol.

Additional file 2. SPIRIT 2013 Checklist: Recommended items to address in a clinical trial protocol and related documents.

\section{Acknowledgements}

Not applicable.

\section{Authors' contributions}

$A C B, B R A, A F C$, AS conceived the study, coordinated its design, drafted and wrote the manuscript. ACB, BRA, AFC, AS, EDS, EMR, ACD, CAS, ARM and AS read and were involved in critical appraisal and revision of the manuscript. All authors approved the final manuscript prior to submission.

\section{Funding}

The trial is partially funded by Sanofi : Sanofi will provide sarilumab free of charge to the study centers and finances the eCRF. Sanofi will have no role in the study's design, collection, management, analysis and interpretation of data, writing of the report and the decision to submit the report for publication

\section{Availability of data and materials}

Chief investigators and the corresponding authors will have access to the final trial dataset. The corresponding authors will evaluate any request for data sharing and will consult with the steering committee after the publication of the main results. Requests can be sent to mariabelen. ruiz@salud.madrid.org.

\section{Ethics approval and consent to participate}

The Research Ethics Committee (REC) at Hospital Universitario Puerta de Hierro Majadahonda approved protocol SARTRE on May 22, 2020 (Reference: 77/20). The research team certifies that this trial has received ethical approval from the appropriate ethical committee. Informed consent to participate will be obtained from all participants or from their legally authorized representatives.

\section{Consent for publication}

Not applicable.

\section{Competing interests}

The authors declare that they have no competing interests.

\section{Author details}

${ }^{1}$ Clinical Pharmacology Department, Hospital Universitario Puerta de Hierro-Majadahonda, Instituto de Investigación Sanitaria Puerta de Hierro Segovia de Arana, Madrid, Spain. ${ }^{2}$ Infectious Diseases Unit, Internal Medicine Department, Hospital Universitario Puerta de Hierro-Majadahonda, Instituto de Investigación Sanitaria Puerta de Hierro - Segovia de Arana, Madrid, Spain.

Received: 20 July 2020 Accepted: 26 July 2020

Published online: 16 September 2020

\section{Publisher's Note}

Springer Nature remains neutral with regard to jurisdictional claims in published maps and institutional affiliations.

Ready to submit your research? Choose BMC and benefit from:

- fast, convenient online submission

- thorough peer review by experienced researchers in your field

- rapid publication on acceptance

- support for research data, including large and complex data types

- gold Open Access which fosters wider collaboration and increased citations

- maximum visibility for your research: over $100 \mathrm{M}$ website views per year

At BMC, research is always in progress.

Learn more biomedcentral.com/submissions 